ISBN 978-81-936279-8-3

13th International Conference on Trends in Agricultural, Chemical, Environmental and Biological

Sciences (TACEBS-18)

London (UK) June 25-26, 2018

\title{
Analysis of Residues-to-Product-Ratios for Energy assessment: Coconut Biomass in Western Region of Thailand
}

\author{
Kittinun Boonrod $^{1}$,Yupin Yuen Yong ${ }^{2}$, Jumpol Kullavanijaya ${ }^{3}$ and Viroj Lengrugsa ${ }^{4}$ \\ ${ }^{1 *}$ Faculty of Humanities and Social Science, Phetchaburi Rajabhat University, Phetchaburi, Thailand \\ ${ }^{2}$ Faculty of Education, Phetchaburi Rajabhat University, Phetchaburi, Thailand \\ ${ }^{2}$ Materials Planning Division, Provincial Electricity Authority, Bangkok, Thailand \\ ${ }^{3}$ Bureau of the Vector Borne Diseases Control, Ministry of Public Health, Nonthaburi, Thailand
}

\begin{abstract}
This study explores to Residues-to-Product-Ratios (RPR) of coconut which specific of each materials and area. The results are used to a reference for estimate potential of biomass as energy production in Western Region of Thailand. The study founded that of RPR values of Outer Coat, Middle Fibrous Coat, Shell, Upper Core Leave Stalk, Bottom Core Leave Stalk, Leave and Empty Fruit Bunch are 0.28, 0.12, 0.20, 0.09, 0.14, 0.04 and 0.03 in respective. Then, the potential of biomass in Western Region of Thailand is 52.43 ktoe, analyses with Production yield in 2015
\end{abstract}

Keywords: Coconut, Residues-to-Product-Ratios, Biomass, Renewable Energy, Biomass Potential

\section{Introduction}

Coconuts represent another type of key commercial crop for Thailand. When Thailand's western region is divided according to the Department of Alternative Energy and Efficiency's database on biomass energy capacity, the area is composed of zones in the following eight provinces: Prachuap Khiri Khan, Phetchaburi, Ratchaburi, Samut Sakhon, Samut Songkhram, Nakhon Pathom and Suphanburi [1] .According to a report by the Office of Agricultural Economics in 2015, the western region has a total of 0.08 million hectare dedicated to coconut cultivation or 40 percent of the country's coconut planting areas. The present study is focused on Prachuap Khiri Khan Province and Phetchaburi Province as the main study areas. In 2015, both provinces had 0.07 million hectare in coconut plantations, or 88 percent of cultivation areas in the western region, with a total crop yield of 0.28 tons, or 31 percent of national output [2].

According to the data from the Department of Alternative Energy and Efficiency (DEDE), when the chemical properties of biomass materials from coconuts are considered in terms of use as an energy source, biomass materials from coconuts were found to have heat values ranging between $15.40-17.93 \mathrm{MJ} / \mathrm{kg}$. This heat value is higher than that of risk husks $(14.27 \mathrm{MJ} / \mathrm{kg})$ [3]. Furthermore, according to a report on the energy capacity of various coconut components in 2013, the stems, leave stalk, spadix (blossoms) and empty fruit bunches of coconuts from all over the country were found to have hard biomass energy capacity at 207.69 ktoe. The energy capacity of coconut coats was $221.66 \mathrm{ktoe}$, while the energy capacity of the coconut shells was 107.83 ktoe. The above data indicates the capacity of coconuts as a consumable material from coconuts for use as fuel in the production of alternative energy. Nevertheless, the above figures are an aggregate representation of the entire country. Furthermore, certain types of biomass materials obtained from some areas currently offer greater variety in terms of use. This tends to result in a lack of capacity. For example, coconut stalk can be sorted into a variety of components based on the context of utilization, namely, leave stalk can be sued for making brooms, while the stems of the stalks can be used as fuel, etc. 
In studies on the energy capacity of biomass, the main issues to consider are the entire amount of biomass and the remaining amount of available biomass that can be used to accurately estimate biomass energy capacity, which will be a key factor leading to planning for future development. The standard method uses Residue to Product Ratios: RPR and the percentage of biomass remain in area (\%REM). The aforementioned coefficients differ based on the area-specific characteristics such as ecosystem conditions, (soil, water and geographical conditions), all of which affect plant and tree growth, harvesting types and utilization characteristics, etc. [4].

The aforementioned reason led to the formation of the conceptual framework for the present study aimed at exploring Residues to Product Ratios (RPR), which are area-specific to Thailand's western region, and the characteristics of each material. At present, the RPR referred to include only three materials, namely, empty fruit bunches, coats and shells [5]. The findings of the study will provide essential information for synthesizing a broad range of predictions on the energy capacity of biomass materials from coconut cultivation and in proximity with local contexts, thereby providing a database for planning that will benefit energy production and other areas.

\section{Methodology}

The scope of the study was set in two provinces in Thailand, namely, Phetchaburi and Prachuap Khiri Khan where the plantation area is approximately 35 percent and the collective production capacity is approximately 31 percent of all pineapple plantations in Thailand (Fig.1a). In terms of content, only tall coconut trees that produce fruit for making coconut milk were studied. The following three groups of biomass materials were studied: Empty fruit bunches, leave stalks and fruits.

\subsection{Sample Size}

The sample size for the population was determined by using Cochran's method [6], setting the data reliability value at 95 percent. The researcher went into the area to conduct a Crop Cutting Survey at a total of 40 plantations and 10 trade and peel yards. A questionnaire survey was used on 200 farmers.

\subsection{Crop Cutting Survey Method in Coconut Plantations}

In all, 40 coconut plantations were surveyed, setting three survey plots per plantation for a total of 120 survey plots. At each survey site, an experimental plot was designated by measuring the vertical and horizontal spans between each tree and dividing the measured values by half in order to create a rectangular perimeter surrounding the coconut trees as the experimental plot.

The sizes of survey plots were recorded along with their numbers and two types of biomass within the experimental plots were weighted and counted, namely, coconut blossom and coconut leave stalk. For coconut leave stalk, they were cut, weighed and recorded in separate parts as follows: 1. Upper core leave stalk (ULS); 2. Bottom core leave stalk (BLS); and 3. Leaves (LEA). The findings in this part of the study precipitates residue to production ratios analysis (RPR) that leads to predictions of potential of biomass generation (PGM) and available biomass (BMA). The equation used in analysis is shown in Table 1. 

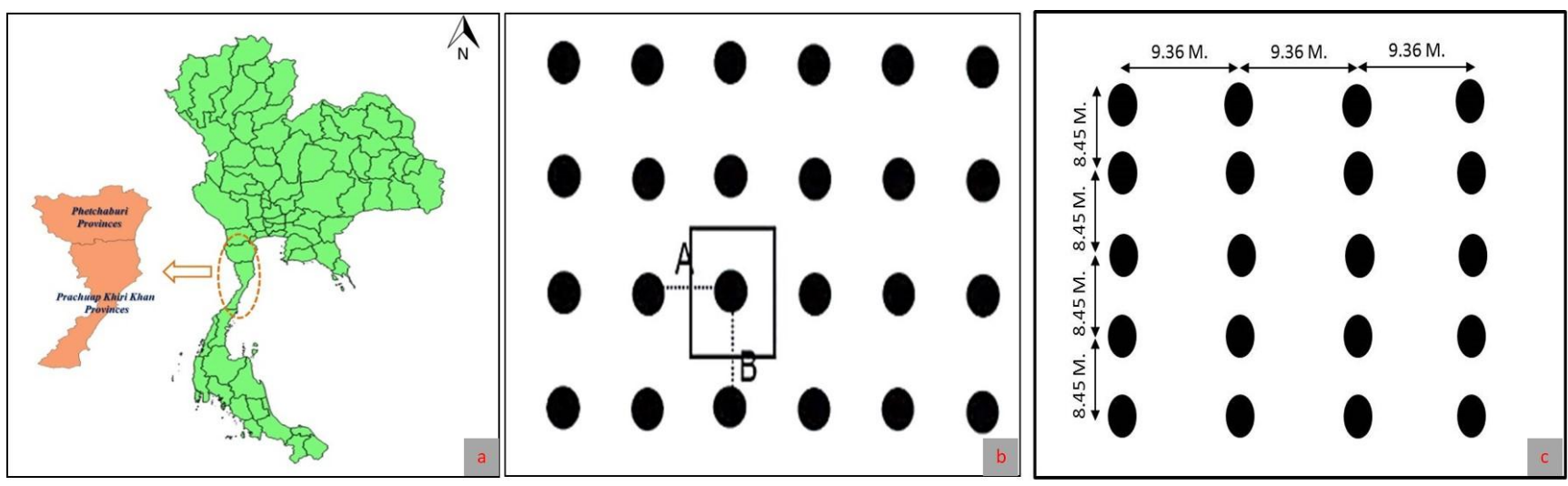

Fig. 1: (a) Target study area (b) Method for Sampling on Site Survey

(c) Number of Coconut Trees per Rai (Thailand Unit, 1 hectare $=6.25$ Rai)

\subsection{Material Survey Method at Peel Yards}

A random survey was conducted in 10 coconut peel yards, and 20 coconuts/peel yard were randomly selected. The randomly sampled coconuts were weighed, peeled and reweighed for each component. The results were recorded for each of the following components: 1. Coconut fruit (FRU); 2. Outer coat (OTC); 3. Middle fibrous coat (MFC); 4. Shell (SHE); and Solid and Liquid endosperm (SLE). The findings obtained in this part led to the analysis and prediction of available biomass (the analysis method is shown in Table 1).

TABLE I: All equations for analysis

\begin{tabular}{|l|l|}
\hline \multicolumn{1}{|c|}{ Equations } & \multicolumn{1}{c|}{ Remark } \\
\hline $\mathrm{RPR}_{\mathrm{i}}=\left(\mathrm{W}_{\mathrm{i}} * \mathrm{~N}_{\mathrm{i}}\right) /\left(\mathrm{N}_{\mathrm{FRU}} * \mathrm{~W}_{\mathrm{FRU}}\right)$ & $\mathrm{RPR}=$ Residue to Product Ratios (no unit) \\
& $\mathrm{PBG}=$ Potential of Biomass Generation (tons/year) \\
$\mathrm{PBG}_{\mathrm{i}}=\mathrm{PY} * \mathrm{RPR}_{\mathrm{I}}$ & $\mathrm{BMA}=$ Biomass Available (tons/ year) \\
& $\mathrm{W}_{\mathrm{i}}=$ Weight of Biomass (kg.) \\
$\mathrm{BMA}_{\mathrm{i}}=\% \mathrm{REM}_{\mathrm{i}} * \mathrm{BMG}_{\mathrm{I}}$ & $\mathrm{N}_{\mathrm{i}}=$ Number of Biomass (no./ hectare/year) \\
& $\mathrm{PY}=$ Production yield by area (tons/ year) \\
& $\% \mathrm{REM}=$ Percentage of biomass remain in area \\
& $\mathrm{i} \quad=$ Category of Biomass \\
\hline
\end{tabular}

\section{Result}

\subsection{Crop Cutting Survey Result}

The result of plantation distance in area, indicated that the depth plantation line (distance B in Fig. 1b) averaged 8.45 meters and the average distance between the trees (distance A in Fig. 1b) was 9.36 meters. So, analyses to 125 trees of coconut were planted per hectare or 20 trees of coconut per rai (Fig.1c).

According to the findings, the weight and proportions of biomass are composed of fruits, leave stalk and empty fruit bunches. The details of these results are shown in Table 2.

\subsection{Questionnaire Survey Results}

Amount of Product per Year: According to the study, the age of coconuts in the studied areas is rather high with the mean age at about 48 years. Coconut trees still able to generate produce account for 82.20 percent of all coconut trees, although decreased productivity was found. A single coconut tree is able to produce 10.92 times per year with the harvest cycle at 34.60 days per time. On average, 2.08 bunches are harvested each time at 7.36 fruits per time or about 167 coconuts per tree per year.

In summarizing the combined analysis of the aforementioned findings both in terms of number of trees per hectare and rate of productivity, coconuts are able to produce 17,156 fruits per hectare per year $\left(\mathrm{N}_{\mathrm{OTC}}, \mathrm{N}_{\mathrm{MFC}}\right.$, $\mathrm{N}_{\mathrm{SHE}}, \mathrm{N}_{\mathrm{SLE}}, \mathrm{N}_{\mathrm{FRU}}$ ) and coconut biomass is composed of key components, namely, outer coat (OTC), middle 
fibrous coat (MFC) and shell (SHE). The study's findings on the percentage of utilization (\%UTZ) for each component are shown in Table 2.

Amount of Empty Fruit Bunches Created Each Year: The study found that for each occasion farmers are able to harvest an average of 2.08 bunch per time per tree. The mean harvest cycle is 10.92 times per tree per year. Up to 94.23 percent of empty bunches are discarded inside plantations after harvest, while the rest find their way to the peel yard, or 5.77 percent. In summary, the empty blossoms/bunches created amount to 23 blossoms per tree per year or 2,875 blossoms per hectare per year $\left(\mathrm{N}_{\mathrm{EB}}\right)$. The findings on the percentage of utilization are shown Table 2.

At the same time, in terms of the quantity of leave stalks created in each given year, the study found that, normally, dried leave stalks that naturally fall down from coconut trees equal an average of 2.55 leave stalks per tree every 33.69 per day or 27.63 leave stalks per tree per year or 3,456 leave stalks per hectare per year ( $\mathrm{N}_{\text {ULS }}$, $\mathrm{N}_{\mathrm{BLS}}, \mathrm{N}_{\mathrm{LEA}}$ ). Coconut leave stalks can be divided into three parts based on usage, namely, the upper core leave stalk (ULS), leaves (LEA) and bottom core leave stalk or "Kamok" (BLS) (Fig. 3A-3D). The percentages of utilization are shown in Table 1.

\section{Discussion}

This section integrates all of the study's findings in order to create predictions on the quantity and energy capacity of each material based on the primary information obtained from the survey study and related secondary information. Overall, it was found that coconut biomass materials in the western region can be converted into 52.43 kilotons of oil equivalent (ktoe). The details are as follows:

\subsection{Outer Coat (OTC):}

Overall, the coconut biomass materials created from the peeling of produce during sales value increase only constitute a small proportion. For the most part, produce is directly sold to peel yards, also known as "all fruit" sales. The peel yards then peel coconuts for subsequent sales. An important byproduct of the aforementioned process is the outer coat, which is utilized by both peel yards and plantations by sales to coconut fiber weaving factories to produce fiber, although prices are uncertain and lack stability. A single vehicle load (about 700 kilograms) has prices ranging from 3 to 20 US dollars. Thus, utilization in alternative energy production should provide an opportunity to guarantee prices for farmers. According to the study, in the 2015 production year, 90,941 tons of outer coat was produced with 737 tons leftover for utilization each year; this amounts to 0.28 kilotons of oil equivalent of energy capacity (heat value at $16.23 \mathrm{MJ} / \mathrm{kg}$.) (Table 3).

\subsection{Middle Fibrous Coat (MFC)}

Peeled coconuts, which are known locally as "soft fruits", still contain middle fibrous coat. The reason the entire peeling is not removed to the shell level is because the middle fibrous coat is used as a soft cushion material during transportation. Coconuts are generally transported for sale in markets, and presently, all middle fibrous coat is discarded and commercialization is absent. However, analysis places its energy capacity at 15.02 ktoe, the details of which are shown in Table 3.

TABLE II: All results of study

\begin{tabular}{|c|c|c|c|c|c|c|c|c|c|c|}
\hline \multirow{3}{*}{ Result } & \multicolumn{9}{|c|}{ Biomass Categories } & \multirow{3}{*}{$\begin{array}{l}\text { Bunch }(n=228) \\
\text { EB }\end{array}$} \\
\hline & \multicolumn{5}{|c|}{ Fruit $(n=200)$} & \multicolumn{4}{|c|}{ Leave Stalk $(n=267)$} & \\
\hline & OTC & MFC & SHE & SLE & FRU & ULS & BLS & LEA & $\mathbf{L S}$ & \\
\hline${ }^{\mathrm{A}} \mathbf{W}$ & 0.62 & 0.27 & 0.43 & 0.87 & 2.19 & 0.95 & 1.48 & 0.43 & 2.86 & 0.34 \\
\hline $\mathbf{N}$ & 17,156 & 17,156 & 17,156 & 17,156 & 17,156 & 3,456 & 3,456 & 3,456 & 3,456 & 2,875 \\
\hline$\%$ UTZ & B 99.19 & 0 & ${ }^{\mathrm{B}} 91.30$ & 100 & 100 & 5.75 & 4.80 & 11.13 & - & 3.95 \\
\hline \% REM & 0.81 & 100 & 8.70 & 0 & 0 & 94.25 & 95.20 & 88.87 & - & 96.05 \\
\hline RPR & 0.28 & 0.12 & 0.20 & - & - & 0.09 & 0.14 & 0.04 & 0.26 & 0.03 \\
\hline
\end{tabular}

\footnotetext{
${ }^{\mathrm{A}}$ as received basis ${ }^{\mathrm{B}}$ data from Department of Alternative Energy Development and Efficiency [3]
} 

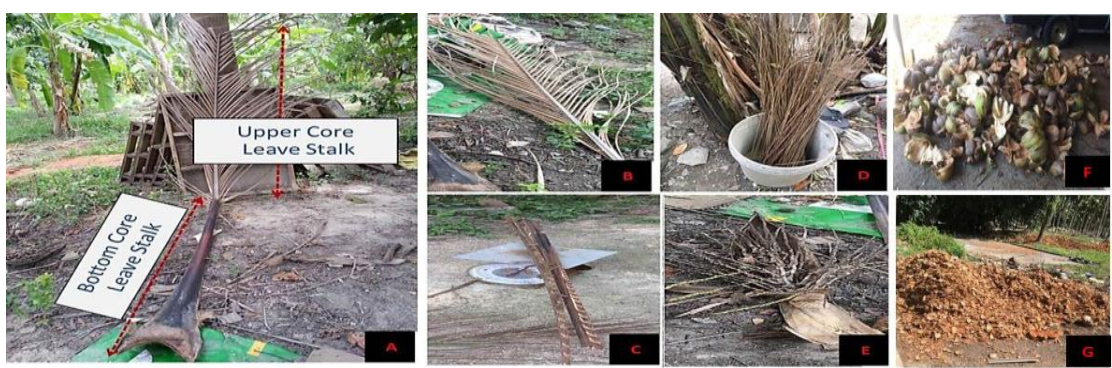

Fig 3: (A) Composition of leave stalk (B) Upper leave stalk with leave (C) Upper core leave stalk for sell (D) Leave, core for sells (E) Empty fruit bunch (F) Outer coat (G) Middle fibrous coat and shell
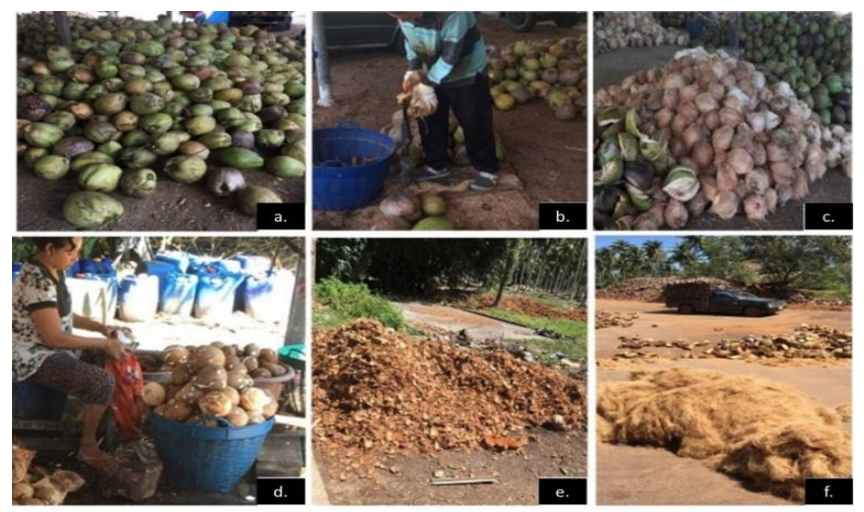

Fig 4: (a) All fruit coconuts sold and sent to shops; (b.-c.) All fruit peeling at fruit peeling yards; (d.) Black fruits scoured into white fruits for added value; (e.) Biomass materials

TABLE III: Energy potential from coconut residues in western region of Thailand

\begin{tabular}{llllllll}
\hline Biomass & ${ }^{\mathrm{A}}$ PY & RPR & \% REM & PBG & BMA & ${ }^{\mathrm{B}} \mathbf{H V}$ & ${ }^{\mathrm{C}}$ ktoe \\
\hline OTC & 324,788 & 0.28 & 0.81 & 90,941 & 737 & 16.23 & 0.28 \\
MFC & 324,788 & 0.12 & 100 & 38,975 & 38,975 & 16.23 & 15.02 \\
SHE & 324,788 & 0.2 & 8.7 & 64,958 & 5,651 & 17.93 & 2.41 \\
ULS & 324,788 & 0.09 & 94.25 & 29,231 & 27,550 & 16 & 10.47 \\
BLS & 324,788 & 0.14 & 95.2 & 45,470 & 43,288 & 16 & 16.44 \\
LEA & 324,788 & 0.04 & 88.87 & 12,992 & 11,546 & 16 & 4.39 \\
EB & 324,788 & 0.03 & 96.05 & 9,744 & 9,359 & 15.4 & 3.42 \\
\hline
\end{tabular}

${ }^{\mathrm{A}}$ Production Yield, amount of Western region (tons/ year) [2] ${ }^{\mathrm{B}}$ Heat value $(\mathrm{MJ} / \mathrm{kg})$ data from [5]

${ }^{\mathrm{C}} \mathrm{ktoe}$ is kilo ton of oil equivalent, $1 \mathrm{ktoe}=42,120,000 \mathrm{MJ}[3]$

\subsection{Shell (SHE)}

At large peel yards, one-stop business is practiced covering plantation coconut auctions, peeling and milk coconut sales. However, the majority of minor peel yards conclude their activities only in the soft fruit stage, with only some peel yards found to continue operations to include peeling coconuts down to the shell level or even to the "white fruit" stage by using blades to scrape coconut shells until the white coconut flesh is reached. An important by product in this stage is the coconut shell. At present, charcoal bar factories accept coconut shells for purchase; they purchase both piece shells and charcoal shells from peel yards and farmers who burn 
charcoal for hire. Analysis places the energy capacity of coconut shell at $17.93 \mathrm{ktoe}$, the details of which are specified in Table 3.

\subsection{Upper Core Leave Stalk (ULS)}

This part constitutes the upper portion of the coconut leave stalk, spanning from the first to the final leaves. Some farmers discard them in the plantation. Others collect them and remove them from the plantation because income can presently be generated for farmers from them. When all of the leaves in the upper core leave stalk are removed, buyers will purchase this part, also known as "stalk cores", for use as burning fuel in earthenware kilns, especially for water jars. Water jar manufacturers claim that fuel obtained from this part of coconut contains some types of essential oils that help in the glazing of jars and earthenware and make them more attractive. Buyers purchase them at the price of 35 pieces per US dollar. Analysis places the energy capacity of upper core leave stalk at 10.74 ktoe, the details of which are specified in Table 3.

\subsection{Leaves (LEA)}

When farmers sell stalk cores to buyers, the leaves removed from the stalks are utilized by using blades to remove the leave tissue portion until only leave cores remain. These are gathered and sold to buyers who manufacture coconut brooms. The mean sales price is 0.5 US dollars. Analysis place the energy capacity of leaves at $4.38 \mathrm{ktoe}$, the details of which appear in Table 3.

\subsection{Bottom Core Leave Stalk (BLS)}

This portion constitutes the part from the area attached to the tree to the first leaf in the upper part. Locally known as "kamok", it is a scrap from the sale of upper cores. Buyers claim that its moisture is why buyers do not purchase kamok. In addition, product transportation is encumbered when the kamom is not cut away. Presently, no commercial utilization is present and only some burn the dry parts to repel insects or as household fuel. Analysis places the energy capacity of the bottom core leave stalk at 16.44 ktoe (Table 3).

\subsection{Empty Fruit Branches (EB)}

According to the survey on farmers, the coconut blossoms found in coconut plantations are created from the following two events: 1 . Natural falls; monkeys are employed in the harvest of very tall coconut trees (special coconut harvest training schools exist for monkeys), and the monkeys will twist off the coconut fruits until they fall to the ground; the coconut blossoms remain attached in the canopy and naturally fall down once dry; 2. Product harvest by cutting; this case occurs in coconuts that are not yet very tall and for which poles can be used or harvesters could climb to harvest the fruits; in doing so, the entire blossom is cut down to save time, leading to an entire blossom of coconuts together to be referred to as a "coconut bunch". When an entire blossom is cut down, only the fruits are removed for subsequent sales, leaving the rest behind. At present, commercial utilization of empty coconut blossoms is still absent. However, they are burned to repel insects or as household fuel. According to analysis, the energy capacity of coconut blossoms is 15.4 ktoe (Table 3 ).

\section{Conclusion}

The present study was aimed at studying the potential contained in the quantity of biomass created from coconut cultivation with focus on creating ratios of residue to product ratios (RPR) specific to the studied areas to represent cultivation areas in the western region with the aim creating accurate predictions on biomass available and energy capacity consistent with local contexts. The research findings indicated specific residue to product ratios for each component. This leads to more detailed and precise quantity predictions for future utilization. For example, the ratio of outer coat to product is 0.28 , while the ratio of middle fibrous coat to product is 0.12 . Previously, these were combined as the ratio of coat and bunch of 0.33 . Additionally, the ratio of the upper core leave stalk to product has been specified at 0.10 , while the ratio of the lower core leave stalk to product was at 0.14 and the ratio of leaves to product was at 0.04 . None of the aforementioned information has previously been made available in the database of the Department of Alternative Energy and Efficiency (Table 
4), although assessment of energy capacity from agricultural waste materials in 2000 did produce a congregated ratio value of both stalks and leaves to product of 0.23 [5].

TABLE IV: The comparisons of RPR values

\begin{tabular}{llllllllll}
\hline \multirow{2}{*}{ Result } & \multicolumn{2}{l}{ Fruit Coat } & \multicolumn{4}{c}{ Leave Stalk } & & Empty \\
\cline { 2 - 8 } & OTC & MFC & SHE & ULS & BLS & LEA & LS & \\
\hline RPR ( ( $^{\text {nd }}$ data) & $0.33^{\mathrm{a}}$ & $0.33^{\mathrm{a}}$ & $0.25^{\mathrm{a}}$ & n.a. & n.a. & n.a. & $0.23^{\mathrm{b}}$ & $0.29^{\mathrm{a}}$ \\
RPR (from study) & 0.28 & 0.12 & 0.20 & 0.09 & 0.14 & 0.04 & 0.26 & 0.03 \\
\hline
\end{tabular}

${ }^{\mathrm{a}}$ data from [3] ${ }^{\mathrm{b}}$ data from [3]

\section{Acknowledgements}

We would to thank Energy Conservation Promotion Fund of Thailand (ENCON) for providing the fund for this research. Also with, Phetchaburi Rajabhat University for supporting in conference.

\section{Reference}

[1] Department of alternative Energy Development and Efficiency (DEDE)., 2015, Alternative Energy Development Plan: AEDP2015 (In $\quad$ Thai), Retrieved $\quad$ January $16, \quad$ from http://www.dede.go.th/download/files/AEDP2015_Final_version.pdf

[2] Office of Agricultural Economics., 2016, Agriculture Statistic of Thailand 2015, Nation Office of Buddhism Press, pp. 64-66. (In Thai)

[3] Department of Alternative Energy Development and Efficiency. 2013. Biomass Potential of Thailand [Online], Available: http://biomass.dede.go.th/biomass_web/index.html [1 August 2017]. (In Thai)

[4] Ezekiel, A.A, Francis, K. and Ahmad, A., 2015, "Technical Analysis of Crop Residue Biomass Energy in an Agricultural Region of Ghana," Resources Conservation and Recycling, 96, pp. 51- 60.

https://doi.org/10.1016/j.resconrec.2015.01.007

[5] Department of Alternative Energy Development and Efficiency. 2000. Biomass Potential of Thailand. [Online], Available: http://www2.dede.go.th/renew/bio_p.htm [1 March 2018]. (In Thai)

[6] Cochran, W.G. (1963). Sampling Techniques, 2nd Ed., New York: John wiley and Sons, Inc. 